\title{
Encapsulação de ácidos nucleicos em nanotubos de carbono: termodinâmica e cinética
}

\author{
Fernando J.A.L. Cruz* e José P.B. Mota \\ LAQV-REQUIMTE, Departamento de Química, Faculdade de Ciências e Tecnologia \\ Universidade Nova de Lisboa. fj.cruz@fct.unl.pt
}

\begin{abstract}
Encapsulation of nucleic acids in carbon nanotubes: thermodynamics and kinetics - Selective and controlled delivery of genetic cargo to a living cell, using encapsulation into nanoporous solids, involves a three step kinetics: i) confinement of the biomolecule, followed by ii) diffusion along the endohedral volume, and finally iii) ejection of the biological material towards the cellular interior. In order to study the thermodynamic and kinetic properties associated with the process, we employ atomically detailed computer experiments to probe the encapsulation of double-stranded canonical B-DNA, $\left(5^{\prime}-D\left({ }^{*} C P^{*} G P^{*} C P * G P * A P * A P * T P^{*} T P^{*} C P * G P * C P * G\right)-3\right.$ '), into hydrophobic and hydrophilic carbon nanotubes with diameters in the range $D=3-4 \mathrm{~nm}$. For that purpose, Classical Molecular Dynamics simulations are run coupled with well-tempered metadynamics and umbrella sampling algorithms. Physiological conditions employed $(310 \mathrm{~K},[\mathrm{NaCl}]=134 \mathrm{mM})$ allow the extrapolation of results to in vivo systems, constituting a landmark for biomolecular encapsulation in the context of cellular delivery.
\end{abstract}

A

entrega controlada e seletiva de material genético à célula viva, recorrendo à encapsulação em sólidos nanoporosos, é um mecanismo de três fases: $i$ ) confinamento da biomolécula, seguida de ii) difusão ao longo do poro e, finalmente, iii) ejeção da carga biológica em direção ao interior da célula. De forma a estudar as propriedades termodinâmicas e cinéticas envolvidas no processo, utilizam-se experiências computacionais ao nível atómico para sondar o confinamento de duplas hélices de B-DNA canónico (5'-D $\left({ }^{*} \mathrm{CP} * \mathrm{GP} * \mathrm{CP} * \mathrm{GP} * \mathrm{AP} * \mathrm{AP} * \mathrm{TP} * \mathrm{TP} * \mathrm{CP} * \mathrm{GP} * \mathrm{CP} * \mathrm{G}\right)-3$ ') em nanotubos de carbono de características hidrofóbicas e hidrofílicas, utilizando diâmetros na gama $D=3-4 \mathrm{~nm}$. Para o efeito, realizam-se simulações de Dinâmica Molecular Clássica acoplada a algoritmos de metadinâmica (well-tempered) e amostragem de chapéu de chuva (umbrela sampling). A utilização de condições fisiológicas $(310 \mathrm{~K},[\mathrm{NaCl}]=$ $134 \mathrm{mM}$ ) permite extrapolar os resultados obtidos para sistemas in vivo, constituindo assim uma contribuição pioneira na área do encapsulamento de moléculas biológicas com vista à entrega celular.

\section{Introdução}

Desde a sua preparação em laboratório pelos grupos de Iijima e Bethune [1-3], os nanotubos de carbono de parede única (SWCNTs) são considerados um dos pilares fundamentais da nanotecnologia. Devido às suas propriedades mecânicas, elétricas e físico-químicas [4], vários estudos têm-nos proposto para aplicações tão diversas [5] como design de compósitos [6], sensores químicos [7], agentes de separação de vapores orgânicos [8] e nanomateriais para armazenamento de $\mathrm{H}_{2}$ e $\mathrm{CH}_{4}[9,10]$.

Geralmente são sintetizados recorrendo a técnicas de deposição de vapor químico (CVD) ou descarga de arco elétrico [4,11,12], conduzindo a sólidos puramente hidrofóbicos; podem no entanto ser modificados com o objetivo de se obter uma distribuição de carga elétrica positiva: i) dopando quimicamente a rede de grafeno com dopantes do tipo $p$, ii) aplicando um campo elétrico ao longo do sistema, e/ou iii) utilizando estratégias de funcionalização química [13-15]. Sob o ponto de vista geométrico, os SWCNTs são essencialmente estruturas unidimensionais (1D) que podem ser racionalizadas pensando numa folha de grafite dobrada no espaço de acordo com um certo vetor diretor. O cilindro resultante é constituído por uma malha hexagonal de átomos de carbono $s p^{2}$, circunscrevendo um volume interno de diâmetro $D$ (Figura 1), e formando assim um paradigma para estudar a adsorpção física de moléculas orgânicas leves $\left(\mathrm{CH}_{4}, \mathrm{C}_{2} \mathrm{H}_{4}, \mathrm{C}_{2} \mathrm{H}_{6}, \mathrm{C}_{3} \mathrm{H}_{6}, \mathrm{C}_{3} \mathrm{H}_{8}, \mathrm{CO}_{2}, \mathrm{CO}\right) \mathrm{em}$ sólidos nanoporosos [10,16-21].
Quando carregados eletricamente, os nanotubos de carbono podem interagir de forma seletiva com macromoléculas biológicas, tais como proteínas e ácidos nucleicos, de forma semelhante à condução biomolecular através de canais na membrana celular, tais como o poro de $\alpha$-hemolisina [22,23]. Sendo a entidade responsável pela transmissão de informação genética entre gerações, o ácido desoxirribonucleico (DNA) é uma molécula fundamental para as ciências da vida. Os estudos pioneiros de Watson e Crick permitiram decifrar a estrutura da dupla hélice de DNA [24], e muito se tem acrescentado desde então ao manancial de informação disponível sobre ácidos nucleicos. À semelhança dos SWCNTs, também a molécula de DNA pode ser considerada como uma entidade $1 \mathrm{D}$, com as respetivas nucleobases alinhadas ao longo de um eixo central que percorre toda a dupla hélice (Figura 1).

Dada a semelhança dimensional entre a molécula de DNA e os SWCNTs, sistemas mistos contendo o ácido nucleico encapsulado no nanoporo foram recentemente propostos como formas alternativas de entregar (seletivamente) material genético ao interior de células. A entrega controlada de cargas biológicas utilizando esta estratégia [26,27] ajuda a mitigar os problemas clássicos associados à terapêutica via oral, que geralmente conduzem à degradação das biomoléculas causada pelas condições drásticas de $\mathrm{pH}$ características do trato gastrointestinal. Geng et al. $[28,29]$ demonstraram recentemente a penetração espontânea de nanotubos através da bicamada lipídica de um 

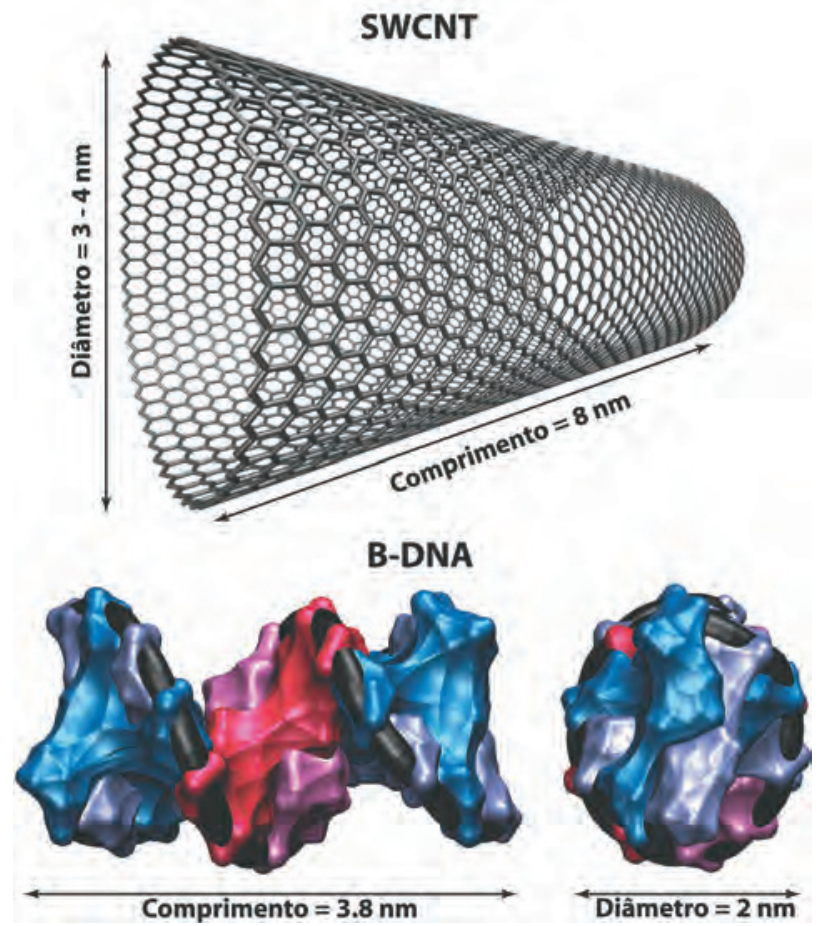

Figura 1 - Cima) Nanotubo de carbono de parede única: o sólido é representado pela malha de ligações $s p^{2} \mathrm{C}-\mathrm{C}$. Baixo) Dodecâmero de Dickerson da forma canónica de B-DNA, 5'-D ${ }^{*} \mathrm{CP} * \mathrm{GP} * \mathrm{CP} * \mathrm{GP} * \mathrm{AP} * \mathrm{AP} *$ $\mathrm{TP} * \mathrm{TP} * \mathrm{CP} * \mathrm{GP} * \mathrm{CP} * \mathrm{G})-3$ ' [25]. As nucleobases individuais são coloridas de acordo com a sua natureza química: (encarnado) adenina, (púrpura) timina, (azul) guanina e (azul claro) citosina; o esqueleto de fosfatos é representado por uma linha negra ao longo da dupla hélice. Figura adaptada da ref. [41]. Copyright (2016) American Chemical Society.

lipossoma, formando um híbrido que é incorporado em células vivas de mamíferos e que atua como um nanoporo através do qual fluem iões e DNA em direção ao interior da célula; o mecanismo global depende fortemente das diferenças de pressão osmótica através da membrana celular [29].

Para poder ser considerada uma forma eficaz e segura de terapêutica para o Homem, os sistemas DNA@SWCNT necessitam prementemente de serem caracterizados quanto à dinâmica e energética dos fenómenos que conduzem ao encapsulamento. O mecanismo global $[27,30]$ é descrito por uma cinética de três passos: $i$ ) encapsulação da biomolécula no nanotubo, seguida de ii) difusão ao longo do nanoporo e finalmente iii) saída/ejeção do material biológico em direção ao interior celular.

O presente trabalho aborda estes aspetos utilizando uma metodologia derivada da mecânica estatística, combinando Dinâmica Molecular Clássica (CMD) com Metadinâmica (well-tempered) e amostragem de chapéu de chuva (umbrella sampling), escolhendo sistemas modelo para descrever os nanotubos e as cadeias de DNA; para o efeito, utilizam-se dois tipos distinctos de nanotubos, hidrofóbicos e hidrofílicos. Torna-se importante salientar que são utilizadas condições fisiológicas em todos os sistemas estudados $(310 \mathrm{~K}, 1 \mathrm{bar},[\mathrm{NaCl}]=134 \mathrm{mM})$, permitindo assim aos resultados e conclusões serem extrapoláveis para sistemas in vivo. Os métodos e moléculas utilizados são descritos na Secção seguinte, os resultados obtidos apresentados e discutidos ao longo da Secção 3 e finalmente estabelecem-se algumas considerações gerais na Secção 4.

\section{Moléculas e Métodos}

\subsection{DNA, solvente fisiológico e SWCNTs}

Todas as moléculas utilizadas no presente trabalho são descritas utilizando campos de força atomísticos, incluindo carga elétrica em cada átomo; considerando a natureza atomística dos modelos, os híbridos DNA@SWCNT contêm 1,5-1,8 x $10^{5}$ partículas. As energias dispersivas são calculadas utilizando o potencial $(12,6)$ de Lennard-Jones e regras de mistura de Lorentz-Berthelot [31, 32]. Á dupla hélice de DNA é conferida flexibilidade total, utilizando para o efeito o campo de forças AMBER99sb-ildn [33,34], e incluindo os refinamentos propostos por Lindorff-Larsen et al. [34]. A parametrização clássica de Åqvist e Dang [35] é utilizada para descrever o par iónico $\mathrm{Na}^{+} \mathrm{Cl}^{-}$, $[\mathrm{NaCl}]=134$ $\mathrm{mM}$, e o modelo de 3 centros proposto por Jorgensen e colaboradores para descrever as moléculas de $\mathrm{H}_{2} \mathrm{O}$ [36]. A forma canónica B-DNA é a conformação predominante em células vivas, e portanto utiliza-se o dodecâmero de Dickerson [25], 5'-D(*CP*GP*CP*GP*AP*AP*TP*TP*CP $\left.{ }^{*} \mathrm{GP} * \mathrm{CP} * \mathrm{G}\right)-3$ ' (Figura 1), para estudar o encapsulamento de ácidos nucleicos. Apesar de possuir um comprimento inferior ao seu análogo genómico, o dodecâmero de Dickerson possui características estruturais semelhantes ao DNA de $\lambda$-bacteriófagos [37], tais como o raio de giração e o diâmetro da dupla hélice, $R_{\text {Gyr }} \approx 0,7-1 \mathrm{~nm}$ e $D \approx 2 \mathrm{~nm}$, tornando-o o candidato ideal para propósitos biológicos.

Cálculos teóricos anteriores utilizando feixes de nanotubos [38], verificaram a existência de um diâmetro crítico, $D=4.16 \mathrm{~nm}$, para além do qual os sólidos colapsam quando expostos à pressão hidrostática atmosférica. Recentemente, Kobayashi et al. [39] validaram experimentalmente aquele limite superior utilizando uma técnica refinada de deposição de vapor químico, e sintetizaram SWCNTs com $D=4 \mathrm{~nm}$, assim obtendo sólidos de diâmetro maior do que aqueles preparados por CVD convencional. Considerando este importante desenvolvimento experimental, utilizam-se aqui dois nanotubos de diâmetro distincto, ambos de simetria ziguezague e com comprimento $L=8 \mathrm{~nm}$, nomeadamente $D=4 \mathrm{~nm}(51,0)$ e $D=3 \mathrm{~nm}(40,0)$. O efeito de densidade de carga elétrica sobre a encapsulação é monitorizado utilizando nanotubos com cargas elétricas nominais $q=+0.05 \mathrm{e}^{-} / \mathrm{C},[13,14,40,41]$, mimetizando sólidos dopados com agentes do tipo $p$ e nanotubos puramente hidrofóbicos expostos a um campo elétrico; os nanoporos resultantes possuem carga elétrica total $Q=+156 \mathrm{e}^{-}(40,0)$ e $Q=+199 \mathrm{e}^{-}(51,0)$, que é neutralizada em solução adicionando uma quantidade apropriada de $\mathrm{NaCl}$ para obter força iónica fisiológica.

\subsection{Metodologia e Dinâmica Molecular Clássica}

O DNA é inicialmente colocado numa célula de simulação ortorrômbica contendo o SWCNT, $(x \times y \times z)=(11 \times$ $11 \times 15) \mathrm{nm}$, alinhado com o eixo principal do sólido $(\mathrm{z})$ e a uma distância de $0,5 \mathrm{~nm}$ do término mais próximo. A célula é solvatada com $\mathrm{H}_{2} \mathrm{O}\left(\rho=1 \mathrm{~g} / \mathrm{cm}^{3}\right)$, a força iónica do meio ajustada com $\mathrm{NaCl}(134 \mathrm{mM})$ e o sistema monitorizado até atingir o equilíbrio $(p, T)$ (Figura 2).

A implementação técnica e realizada utilizando o motor de CMD Gromacs 4.6.7 [42] e o esquema de Verlet para integrar as equações de Newton com um passo temporal 
de 2 fs; a visualização das trajetórias moleculares é feita com o VMD 1.9.3 [43]. De forma a manter um controlo estricto sobre as condições fisiológicas, utilizou-se um termostato de Nosé-Hoover (310 K) [44,45] e um baróstato de Parrinello-Rahman (1 bar) [46], em solução aquosa de $\mathrm{NaCl}$, e aplicaram-se condições fronteira tridimensionais. Para as interações de Coulomb e de van der Waals truncou-se o potencial a 1,5 nm (cut-off), e aplicou-se o método de malha de partículas de Ewald (particle-mesh) para calcular a eletrostática de longo alcance $[47,48]$ utilizando interpolação cúbica e um espaçamento máximo da rede de Fourier de $0,12 \mathrm{~nm}$.

\subsection{Metadinâmica (well-tempered)}

Por forma a obter superfícies de energia-livre associadas ao mecanismo de encapsulamento, utilizou-se o algoritmo de metadinâmica (well-tempered) proposto por Parrinello e colaboradores [49, 50]. Sumariamente, o método altera a dinâmica de Newton ao introduzir um potencial Gaussiano dependente do tempo, $V(\Phi, t)$, no Hamiltoniano clássico, assim evitando que o sistema fique constantemente preso em mínimos de energia locais e conduzindo a uma exploração mais eficiente do espaço termodinâmico.

O potencial $V(\Phi, t)$ é uma função dos chamados parâmetros de ordem (ou variáveis coletivas), $\Phi(v)=\left[\phi_{1}(v)\right.$, $\left.\phi_{2}(u), \ldots, \phi_{n}(u)\right]$, estando eles próprios relacionados com coordenadas microscópicas do sistema real, $v$, de acordo com a equação 1 :

$$
V[\Phi(v), t]=W \sum_{t^{\prime}=0}^{t^{\prime} s t} \exp \left\{-\frac{v\left[\Phi\left(v\left(t^{\prime}\right)\right) \cdot t^{\prime}\right]}{\Delta T}\right\} \exp \left\{-\sum_{i=1}^{n} \frac{\left[\Phi_{i}(u)-\phi_{L}(u(t))\right]^{2}}{2 \sigma_{i}^{2}}\right\}
$$

onde $t$ é o tempo de simulação, $W=\tau_{G} \omega$ é a altura de um Gaussiano individual, $\tau_{G}$ é o intervalo de tempo a que a contribuição para o potencial $V(\Phi, t)$ é adicionada, $\omega$ é a altura inicial dos Gaussianos, $\Delta T$ é um parâmetro com dimensões de temperatura, $\sigma_{i}$ é a amplitude dos Gaussianos e $n$ é o número de variáveis coletivas do sistema real; no presente caso utilizou-se $\tau_{G}=0,1 \mathrm{ps}, \omega=0,1 \mathrm{~kJ} / \mathrm{mol}, \Delta T=$ $310 \mathrm{~K} \mathrm{e} \sigma_{i}=0,1 \mathrm{~nm}$. De notar que quando $\Delta T \rightarrow 0$, o algoritmo aproxima-se de uma simulação clássica recuperando a dinâmica de Newton.

Uma vez que os nanotubos de carbono são essencialmente 1D simétricos, as superfícies de energia-livre são construídas em função de dois parâmetros de ordem, $\phi_{1}=\left|\overrightarrow{R_{D N A}}-\overrightarrow{R_{S W C N T}}\right|$ e $\phi_{2}=\left|\overrightarrow{R_{G C_{1} 1}}-\overrightarrow{R_{G C_{i}, 12}}\right|$, onde $\vec{R}$ é o vetor posicional do centro de massa da biomolécula $\left(\left(\overrightarrow{R_{D N A}}\right)\right)$ e do nanotubo $\left(\overrightarrow{\left(R_{S W C N T}\right.}\right)$ ), projetado no eixo $z$, ou dos pares base (GC) localizados em términos opostos da dupla-hélice, $\left(\left(\overrightarrow{R_{G C, 1}}\right)\right)$ e $\left(\left(\overrightarrow{R_{G C, 12}}\right)\right)$. Dadas as definições de parâmetros de ordem, $\phi_{1}$ mede a distância entre a molécula de DNA e o centro do nanotubo e $\phi_{2}$ corresponde ao comprimento da dupla-hélice medido entre pares base terminais (GC). Os nanotubos e o dodecâmero de Dickerson possuem comprimentos de $L=8 \mathrm{~nm}$ e $L=3.8 \mathrm{~nm}$ (Figura 1), respetivamente, pelo que qualquer valor $\phi_{1}=\Delta L=\left(L^{\text {SWCNT }}-L^{D N A}\right) / 2<2.1 \mathrm{~nm}$ corresponde a um híbrido DNA@SWCNT onde a biomolécula se encontra completamente encapsulada; a fronteira $\phi_{1}>5.9 \mathrm{~nm}$ indica ausência de encapsulamento.
A superfície tridimensional de energia-livre de Gibbs é construída somando os potenciais Gaussianos de acordo com $F(\Phi, t)=-\{[(T+\Delta T) / \Delta T] V(\Phi, t)\}$. A convergência do método para a obtenção de uma superfície correta encontra-se discutida na literatura $[49,51]$; no limite de tempos suficientemente longos, $[\partial V(\Phi, t) / \partial t] \rightarrow 0$ e a técnica de metadinâmica garante a convergência da respetiva superfície de energia-livre. Uma abordagem alternativa que conduz à energia-livre independente do tempo assenta na integração de $F(\Phi, t)$ ao longo da porção final do cálculo de metadinâmica [51], e portanto a energia-livre é matematicamente obtida a partir da equação 2, onde $t_{\text {tot }}$ é o tempo total de simulação e $v$ é a janela temporal sob a qual a integração é realizada.

$F(\Phi)=-\frac{1}{\vartheta} \int_{t_{\text {tot }-\vartheta}}^{t_{t o t}} V(\Phi, t) d t$

Cruz et al. realizaram [40,52] testes de convergência utilizando janelas de $v=10$ ns e verificaram que a propriedade $F(\Phi)$ tinha convergido após os primeiros 40 ns de simulação.

\subsection{Amostragem de Chapéu de Chuva (umbrella sampling)}

Foram também realizadas simulações independentes utilizando a técnica de amostragem de chapéu de chuva [53,54]. Considerando um sistema composto por $N$ partículas idênticas, o método altera o Hamiltoniano clássico, $H$, que depende da energia potencial, $U\left(r^{N}\right)$, e cinética, $E\left(p^{N}\right)$, adicionando um potencial harmónico e independente do tempo, $V(\Theta)=(k / 2)\left(\Theta-\Theta^{0}\right)^{2}$, de acordo com $H\left(r^{N}, p^{N}, \Theta\right)=U\left(r^{N}\right)+E\left(p^{N}\right)+V(\Theta) ; k$ é a constante de força harmónica ( $k=1 \mathrm{~kJ} / \mathrm{mol}$ no presente trabalho), $\Theta$ é um parâmetro de ordem e $\Theta^{0}=4,1$ nm corresponde à posição da restricão imposta à amostragem de chapéu de chuva; $\Theta=\left|\overrightarrow{R_{G C, 1}}-\overrightarrow{R_{G C, 12}}\right|$ é o comprimento de DNA medido entre nucleobases complementares (GC) localizadas nos términos da dupla hélice, e que é análogo ao parâmetro de ordem $\phi_{2}$ utilizado nos cálculos de metadinâmica.

Quando o potencial $V(\Theta)$ é utilizado no Halmiltoniano, obtém-se uma probabilidade de distribuição do sistema enviesada, $P^{b}(\Theta)$, através de uma distribuição de Boltzmann ao longo de $\Theta$, e portanto assumindo que o sistema é ergódico [54]:

$$
P^{b}(\Theta)=\frac{\int \exp \{-\beta[U(r)+V(\Theta,(r))]\} \delta\left[\Theta^{\prime(r)}-\Theta\right] d^{N_{r}}}{\int \exp \left[-\beta\left[U(r)+V\left(\Theta\left(\theta^{\prime}(r)\right)\right]\right] d^{N_{r}}\right.}
$$

onde $\beta=\left(1 / k_{B} T\right), k_{B}$ é a constante de Boltzmann, é a função delta de Dirac, e $N$ é o número total de partículas do sistema. Uma vez que o potencial $V(\Theta)$ depende apenas do parâmetro de ordem $\Theta$, e a integração do numerador é realizada sobre todos os graus de liberdade exceto $\Theta$, a probabilidade não enviesada do sistema real , $P^{u}(\Theta)$, é obtida a partir da equação 4 :

$$
P^{u}(\Theta)=P^{b}(\Theta) \exp ^{\beta V(\Theta)} \Gamma
$$

onde $\Gamma=-(1 / \beta) \ln \left\langle e^{-\beta V(\Theta)}\right\rangle$ é independente de $\Theta$ e os parênteses triangulares representam uma amostragem feita 
sobre o ensemble. A reconstrução do perfil real (não enviesado) de energia-livre, ou potencial de força média (PMF) [55], consistente com a energia-livre de Gibbs, $P M F(\Theta)=-k_{B} T \ln P^{u}(\Theta)$, é realizada utilizando o método de análise por histogramas médios [55-57].

Todos os cálculos de metadinâmica e amostragem de chapéu de chuva foram realizados em conjunto com as simulações de dinâmica molecular, modificando o código original de CMD com o conjunto de rotinas Plumed 1.2.2 para o cálculo de energia-livre [58].

\section{Resultados e Discussão}

Inicialmente a uma distância de $0,5 \mathrm{~nm}$ do nanotubo (Figura 2a), o ácido nucleico difunde da solução em direção ao término mais próximo (Figura 2b), sujeito a uma atração eletrostática forte $\left(\sim-3,5 \times 10^{3} \mathrm{~kJ} / \mathrm{mol}\right)$. Aí, a dupla hélice equilibra-se dando origem a alguns rearranjos estruturais, e após uma janela temporal de 3,4-15,42 ns, que é função da topologia e carga elétrica do sólido, fica completamente encapsulado (Figura 2c) sendo o único grau de liberdade restante a difusão ao longo do volume interno do nanotubo (Figuras 2d-g).

De forma a tornar a análise mais clara, abordar-se-ão de forma separada as propriedades de equilíbrio e dinâmicas dos híbridos DNA@SWCNT.

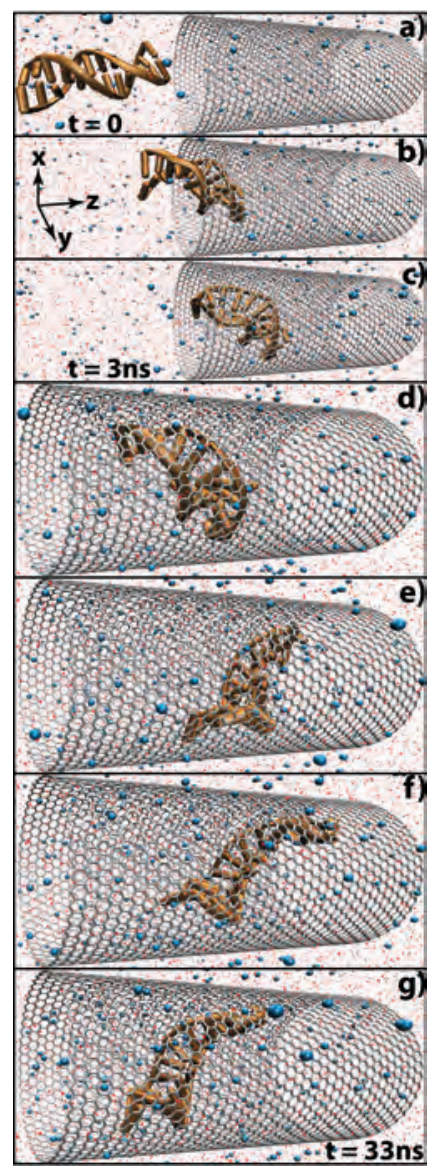

Figura 2 - Trajetória observada para um ácido nucleico exposto a um nanotubo eletricamente carregado e com $D=4 \mathrm{~nm}$. a) Configuração inicial com o DNA a uma distância de $0,5 \mathrm{~nm}$ do término mais próximo, b) a encapsulação começa em consequência de atrações eletrostáticas fortes entre o DNA e o sólido, conduzindo a c) confinamento completo da biomolécula, e seguido de $d-g$ ) translação molecular dentro do volume interno. Legenda: ocre: dupla hélice de DNA; cinzento claro: nanotubo; encarnado: $\mathrm{H}_{2} \mathrm{O}$ e azul: iões de $\mathrm{Na}^{+}$e $\mathrm{Cl}^{-}$. Adaptado de [59].

\subsection{Energias-livres}

As superfícies bidimensionais de energia-livre obtidas a partir do algoritmo de metadinâmica (equações 1 e 2) são representadas na Figura 3, destacando os domínios energeticamente mais estáveis. É de salientar que os resultados foram obtidos em condições isotérmicas e isobáricas (310 K, 1 bar), e, assim, as energias na Figura 3 são equivalentes à energia-livre de Gibbs; o estado de referência corresponde à dupla hélice de DNA em solução eletrolítica, antes de ocorrer encapsulação. É curioso notar que quando a topologia $(40,0)$ é puramente hidrofóbica $(q=0)$, ocorre inibição de encapsulamento por parte do sólido e assim a superfície correspondente não pôde ser determinada, encontrando-se ausente da Figura 3.

Os resultados obtidos para ambos os sólidos $(51,0)$ indicam claramente a existência de vários mínimos locais contidos dentro do nanotubo, $\phi_{1}<2 \mathrm{~nm}$, e ligados entre eles por uma rota termodinâmica que implica uma penalização $\leq 5 \mathrm{~kJ} / \mathrm{mol}$ associada à difusão da molécula entre mínimos adjacentes.
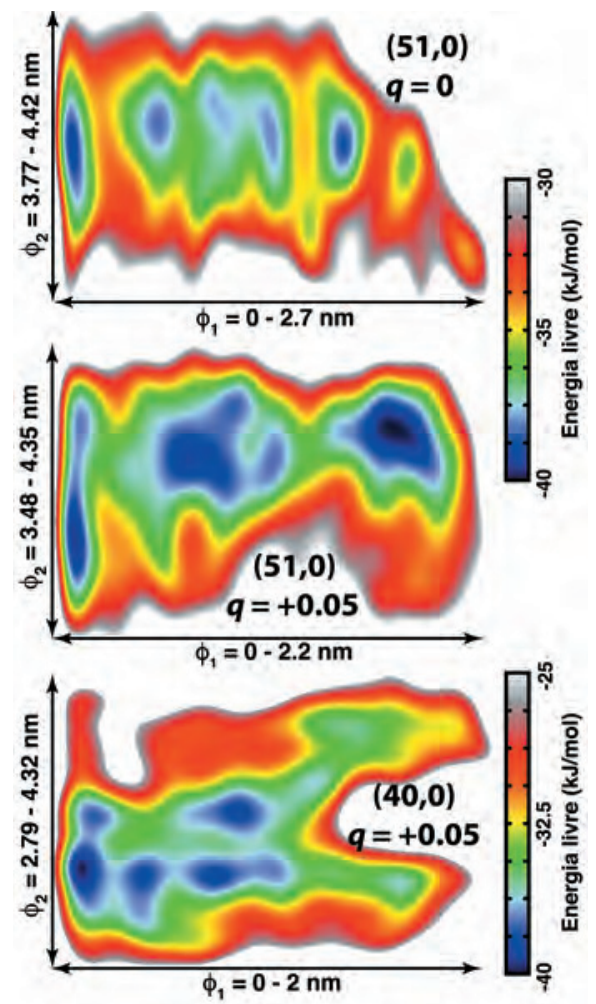

Figura 3 - Superfícies de energia-livre de Gibbs. $\phi$, é a distância entre centros de massa do DNA e do SWCNT, projetada ao longo do eixo principal do nanoporo $(z)$, e $\phi_{2}$ corresponde ao comprimento da dupla hélice. Os mínimos de energia livre encontram-se sempre distribuídos ao longo do volume interno dos nanotubos, $\phi_{1}<2 \mathrm{~nm}$, ligados entre eles por uma rota termodinâmica e com uma penalidade de energia-livre $\leq 5 \mathrm{~kJ} / \mathrm{mol}$. O ensemble completo de mínimos locais é, $\left(\phi_{1}, \phi_{2}\right)$ nm: $(0,12 ; 4,11),(0,62$; $4,16),(1,31 ; 4,16)$ e $(1,80 ; 4,12)$ para $(51,0 ; q=0) ;(0,1 ; 3,78),(0,67 ; 4)$ e $(1,75 ; 4,1)$ para $\left(51,0 ; q=+0.05 \mathrm{e}^{-/ C}\right) ;(0,1 ; 3,31),(0,4 ; 3,25),(0,65 ; 3,25)$, $(0,85 ; 3,6),(1,05 ; 3,25)$ e $(1,2 ; 3,25)$ para $\left(40,0 ; \mathrm{q}=+0.05 \mathrm{e}^{-/ C}\right)$. Figura adaptada da ref. [41]. Copyright (2016) American Chemical Society.

O mínimo absoluto de energia-livre a $\left(\phi_{1}, \phi_{2}\right)=(0,1$; $4,1) \mathrm{nm}(q=0)$ desloca-se para $\left(\phi_{1}, \phi_{2}\right)=(1,7 ; 4,1) \mathrm{nm}$ quando o sólido é eletricamente carregado $\left(q=+0.05 \mathrm{e}^{-} /\right.$ $\mathrm{C})$, indicando que o centro do nanotubo deixa de ser o domínio energeticamente mais favorável. O aumento ligeiro 
no comprimento da dupla hélice de $\phi_{2}=3,8 \mathrm{~nm}$ (correspondente à forma canónica B) para $\phi_{2}=4,1 \mathrm{~nm}$ ocorre através de uma expansão elástica da molécula [52].

Quando o diâmetro do nanotubo é reduzido para $D=$ $3 \mathrm{~nm}$ e mantida uma densidade de carga elétrica não-nula, o mínimo absoluto de energia-livre aparece localizado em $\left(\phi_{1}, \phi_{2}\right)=(1,05 ; 3,25) \mathrm{nm}$; por oposição ao seu análogo puramente hidrofóbico, a topologia carregada $(40,0)$ favorece a encapsulação de ácidos nucleicos. É de salientar que o espaço de fases coberto por $\phi_{2}$ é maior do que nas topologias $(51,0)$, e inclui agora formas não estáveis (transientes) que são o resultado de compressão severa ao longo da dupla hélice $\left(\phi_{2}<3 \mathrm{~nm}\right)$.

De forma a validar os resultados de metadinâmica e simultaneamente conduzir um teste de autoconsistência aos cálculos, realizaram-se simulações independentes utilizando o método da amostragem de chapéu de chuva (equações 3 e 4). Para o efeito, construiu-se um parâmetro de ordem $\Theta$ que por analogia com $\phi_{2}$ corresponde ao comprimento da dupla hélice (Figura 4).

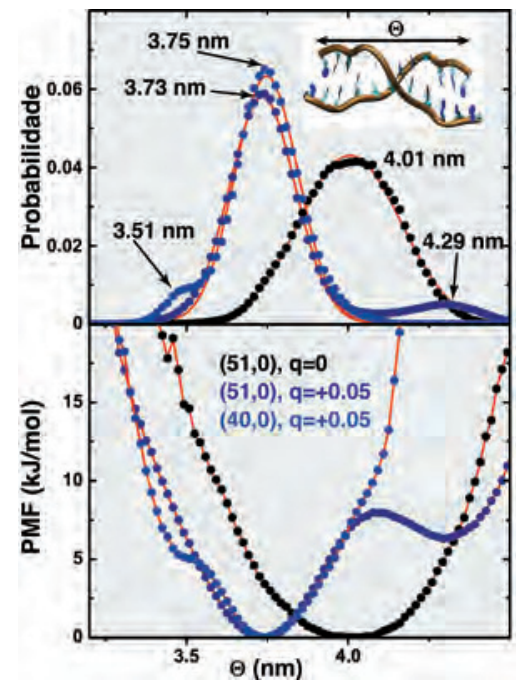

Figura 4 - Probabilidade de distribuição e potencial de força média (PMF) do DNA encapsulado. Porque o parâmetro de ordem $\Theta$ foi definido como o comprimento da dupla hélice, os dois picos observados para as topologias eletricamente carregadas identificam claramente o máximo de probabilidade correspondente às conformações de equilíbrio $(\Theta=3,73-3,75 \mathrm{~nm})$, mas também duas outras formas não canónicas de DNA, a $\Theta=4,29$ e $\Theta=3,51 \mathrm{~nm}$. Símbolos são os resultados das simulações e as linhas correspondem a ajustes utilizando estatísticas de Gauss; preto: $(51,0) q=0$, azul escuro: $(51,0) q=+0.05 \mathrm{e}^{-} / \mathrm{C}$ e azul claro: $(40,0)$ $q=+0.05 \mathrm{e}^{-} / \mathrm{C}$. A curva Gaussiana para a topologia $(40,0)$ foi obtida no intervalo $\Theta>3,5 \mathrm{~nm}$. Figura adaptada da ref. [41]. Copyright (2016) American Chemical Society.

Os perfis são Gaussianos em torno de $\Theta$, com máximos no domínio 3,73-3,75 nm de acordo com os mínimos de energia-livre obtidos para $\phi_{2}$ (Figura 3), e, portanto, consistentes com o comprimento de B-DNA canónico de 3,8 nm. Vimos anteriormente que o confinamento de DNA num SWCNT $(51,0)$ hidrofóbico conduz a uma expansão elástica da dupla hélice de cerca de $0,3 \mathrm{~nm}$, localizada essencialmente em términos opostos [52]. Apesar dos máximos de probabilidade dominarem por completo a paisagem energética, é de notar o aparecimento de duas outras formas de DNA quando $q=+0,05 \mathrm{e}^{-} / \mathrm{C}$, em lados opostos dos picos Gaussianos a $\Theta=4,29 \mathrm{~nm}(51,0)$ e $\Theta=$ 3,51 nm (40,0): o diâmetro de nanotubo desempenha um papel crucial no comprimento assumido por um ácido nucleico encapsulado.

\subsection{Eletrostática}

Considerando apenas os nanotubos eletricamente carregados, os híbridos DNA@SWCNT revelam claramente uma separação de densidade de carga elétrica, $\Gamma(x, y)$ (Figura 5), com contribuições dominantes do próprio sólido mas também do par iónico $\mathrm{Na}^{+} \mathrm{Cl}^{-}$.
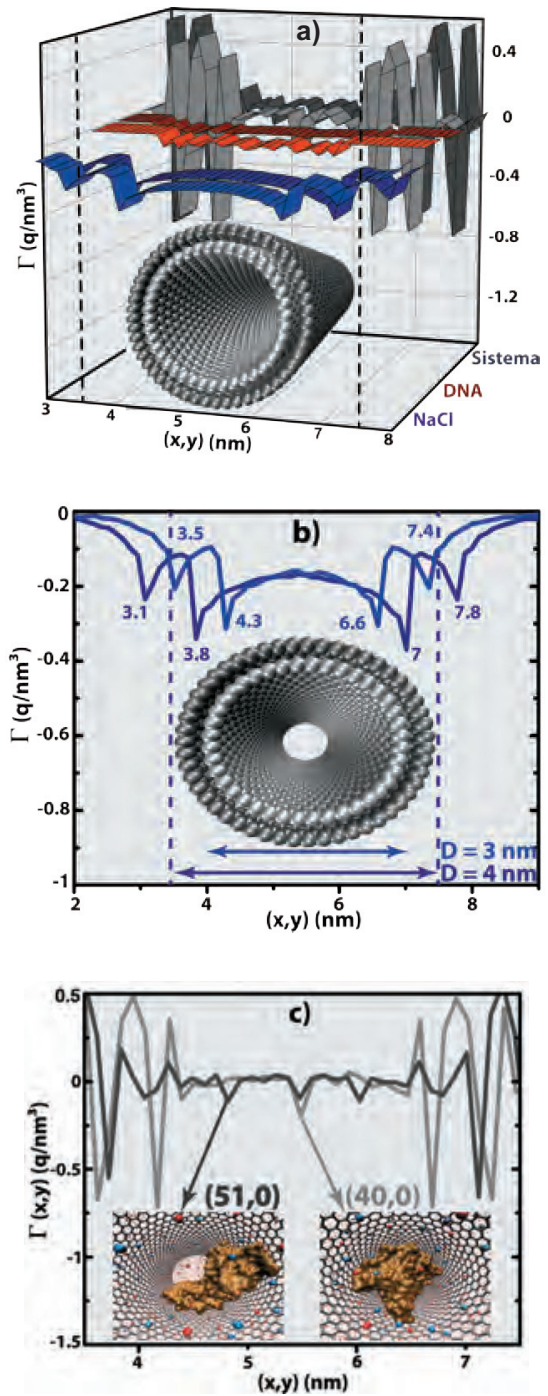

Figura 5 - Densidade de carga elétrica. As caixas de simulação com os híbridos DNA@SWCNT foram divididas em 100 fatias de 0,11 nm de largura, e cada fatia integrada ao longo da direção $x$ ou $y$ para obter uma densidade de carga volumétrica, $(x, y) . a) \mathrm{NaCl}$ (azul), DNA (encarnado), sistemas completos (DNA@SWCNT+ $\mathrm{H}_{2} \mathrm{O}+\mathrm{NaCl}$ ) (cinzento); b) densidade de carga de $\mathrm{NaCl}$ e $c$ ) densidade de carga dos sistemas completos. O DNA é representado por uma superfície ocre, a $\mathrm{H}_{2} \mathrm{O}$ pelos seus átomos de $\mathrm{O}$ (encarnado) e os iões $\mathrm{Cl}^{-}$por esferas azuis. Cores claras e escuras correspondem às topologias $(40,0)$ e $(51,0)$, respetivamente. Os SWCNTs encontram-se alinhados ao longo da direção (z) e assim o seu eixo principal é perpendicular ao plano $(x, y)$; o volume dos sistemas corresponde a $(x \times y \times z)=(11 \times 11 \times 15) \mathrm{nm}($ as linhas a tracejado indicam as fronteiras externas do sólido $(51,0))$. Adaptado de [59].

Os picos na Figura 5b são atribuídos aos iões $\mathrm{Cl}^{-}$, que se encontram em contacto direto com as paredes sólidas e a mediar as interações com o ácido nucleico. Os perfis eletrostáticos obtidos para o $\mathrm{NaCl}$ são na realidade uma fotografia nanoscópica em torno das nanotubos, revelando a existência de blindagem entre a solução e o volume 
interno do poro. Considerando $\xi_{1}$ como a distância entre os picos das paredes externas, 7,8 nm e 3,1 nm $(51,0)$ e 7,4 nm e $3.5 \mathrm{~nm}(40,0)$, e $\xi_{2}$ como a mesma propriedade em relação às paredes internas, $7 \mathrm{~nm}$ e 3,8 $\mathrm{nm}(51,0)$ e 6,6 nm e 4,3 nm $(40,0)$, então existe uma constante de blindagem $\zeta=\left(\xi_{1}-\xi_{2}\right)$, abaixo da qual o sistema encapsulado não possui memória eletrostática da solução: $\zeta^{(40,0)}=1,6 \mathrm{~nm}$ e $\zeta^{(51,0)}=1,5 \mathrm{~nm}$.

Devido à natureza atomística dos nossos modelos, o desdobramento dos picos de $\Gamma(x, y)$ na Figura $5 c$ marca a distinção entre a parede grafítica externa e interna, a última das quais contacta diretamente com a biomolécula. Estando fortemente correlacionada com as paredes, a densidade de carga no volume interno do sólido corresponde essencialmente ao ácido nucleico e aos iões $\mathrm{Cl}^{-}$. É de notar que, dependendo do diâmetro exato do nanotubo, a densidade de carga associada ao DNA está fortemente localizada nas paredes $(D=4 \mathrm{~nm})$ ou concentrada ao longo do centro do nanoporo $(D=3 \mathrm{~nm})$. Esta observação é consequência do volume-livre disponível, pois as energias de interação ácido nucleico/sólido são muito semelhantes para ambas as topologias ( 4,1× $10^{3} \mathrm{~kJ} / \mathrm{mol}$ ) [41]; a molécula de DNA não possui graus de liberdade para se acomodar ao longo do sólido $(40,0)$ exceto na direção $z$ paralela ao eixo principal, inibição essa que é levantada para a topologia $(51,0)$ permitindo assim ao ácido nucleico deformar-se elasticamente e explorar as dimensões $x$ e $y$.

No presente trabalho, o ambiente eletrostático à volta da molécula de DNA é monitorizado utilizando a distribuição de carga associada ao par iónico $\mathrm{Na}^{+} \mathrm{Cl}^{-}$. Para o efeito, determinaram-se os respetivos mapas de densidade numérica (Figura 6) separando as contribuições do catião e do anião. À parte do volume de exclusão correspondente às paredes do sólido, a densidade de $\mathrm{Na}^{+}$encontra-se homogeneamente distribuída dentro e fora dos nanotubos, formando essencialmente uma distribuição de carga contínua. Por oposição, os iões $\mathrm{Cl}^{-}$encontram-se distribuídos em domínios não-homogéneos, e concentrados ao longo das paredes internas, sendo a sua densidade decrescente à medida que se aproxima do centro $(x, y)$ do nanotubo (zona já fortemente populada por carga negativa resultante da biomolécula).

Considerando o eixo principal $z$, torna-se evidente que existe um segundo volume de exclusão, modestamente populado por $\mathrm{Cl}^{-}$, e particularmente evidente na topologia $(40,0)$. Os iões $\mathrm{Cl}^{-}$são da mesma natureza eletrostática que os grupos fosfato do DNA, constituindo assim espécies que são mutuamente exclusivas, sendo portanto empurrados para os términos do sólido onde a densidade de carga elétrica do DNA $\rightarrow 0$. Como veremos adiante ( $c f$. $3.5-\mathrm{Ci}$ nética) este facto provocará efeitos bastante pronunciados sobre a difusão biomolecular ao longo do sólido.

\subsection{Densidade biomolecular}

De forma a analisar inequivocamente a trajetória do ácido nucleico, determinaram-se mapas bi-dimensionais de densidade numérica correspondentes ao DNA (Figura 7), utilizando histogramas temporais para o centro de massa molecular. Os vastos domínios azuis na Figura 7, onde a densidade é aproximadamente nula, são atribuíveis à solução eletrolítica que o DNA nunca (re)visita após ter ocorrido encapsulação. Que a biomolécula confinada retém mobilidade translacional torna-se agora evidente, identi-
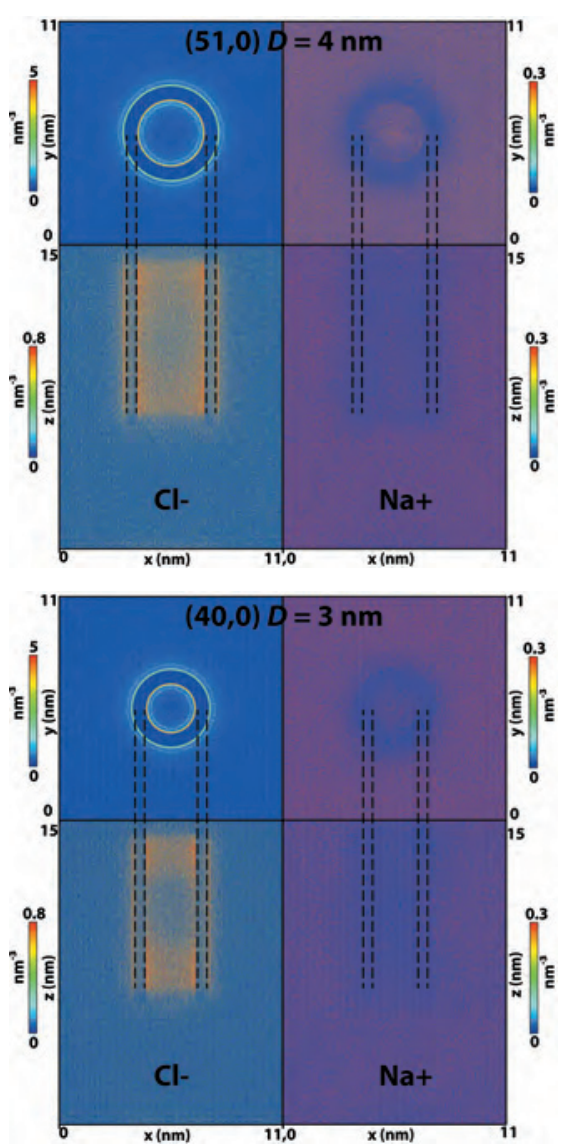

Figura 6 - Mapas de densidade numérica de $\mathrm{Na}^{+} \mathrm{Cl}^{-}\left(q=+0,05 \mathrm{e}^{-} / \mathrm{C}\right)$. É de notar a 2. ${ }^{\text {a }}$ camada de hidratação de iões $\mathrm{Cl}^{-}$em torno nas paredes interna e externa; as linhas a tracejado são representações pictóricas dos limites das mesmas [59].
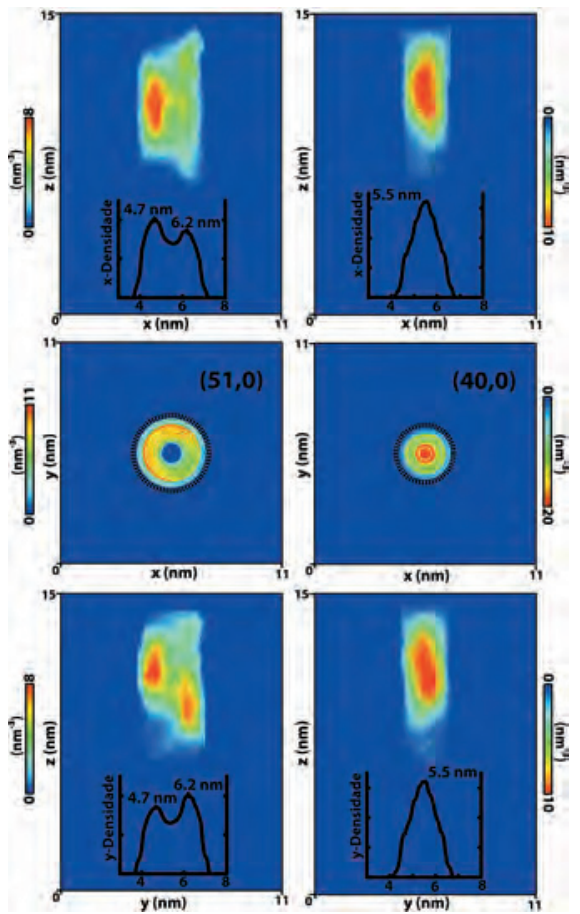

Figura 7 - Mapas de densidade numérica de DNA $\left(q=+0.05 \mathrm{e}^{-} / \mathrm{C}\right)$. Os domínios amarelos e encarnados, onde a densidade se aproxima do máximo, indicam que o DNA mantém mobilidade translacional dentro dos nanoporos; as linhas a tracejado indicam as fronteiras dos SWCNTs e as linhas a preto são perfis de densidade $1 \mathrm{D}$ ao longo da direção respetiva. Note-se o volume vazio na topologia $(51,0)$ ao longo do eixo principal do nanoporo e com um diâmetro cilíndrico de $1.5 \mathrm{~nm}$. Figura adaptada da ref. [41].Copyright (2016) American Chemical Society. 
ficando para o efeito as zonas amarelas e encarnadas dos mapas de densidade; nessas zonas, que cobrem uma grande porção do volume interno do nanoporo, a densidade aproxima-se do valor máximo.

No entanto, e apesar da conservação de mobilidade, os mapas de densidade da Figura 7 revelam também que a difusão molecular é bastante influenciada pelo diâmetro do nanotubo: com um diâmetro de ca. 2 nm (Figura 1), o ácido nucleico é menos constrangido num poro de $D=4 \mathrm{~nm}$, e, assim, devido a razões entrópicas (volume-livre), o respetivo deslocamento molecular é mais inibido num SWCNT com $D=3 \mathrm{~nm}$. Os perfis de densidade 1D indicados na Figura 7 revelam um único pico no caso da topologia $(40,0)$, ocorrendo desdobramento em dois sinais simétricos em torno do centro para o sólido $(51,0)$. Neste último caso, observa-se uma distância entre picos de $1.5 \mathrm{~nm}$, que permite inferir acerca da existência de um domínio cilíndrico vazio ao longo do eixo principal, onde a densidade se aproxima de zero; além disso, aqueles dois picos estão em contacto próximo com as paredes eletricamente carregadas, indicando que o DNA é agora completamente móvel no plano $(x, y)$.

\subsection{Eixos de dupla hélice}

A mobilidade molecular entre fronteiras sólidas ocorre via um processo de autodifusão ( $c f .3 .5$ - Cinética), mas o ácido nucleico também recorre a um mecanismo que envolve rotação em torno do eixo molecular.

Por forma a conseguir visualizar este último fenómeno em detalhe, o dodecâmero de Dickerson (Figura 1) foi separado nas duas cadeias que o constituem, e cada uma delas foi utilizada para monitorizar o espaço de fases. Atribuindo cores distintas a cada eixo de cadeia única, os resultados encontram-se graficamente ilustrados na Figura 8 para dife-

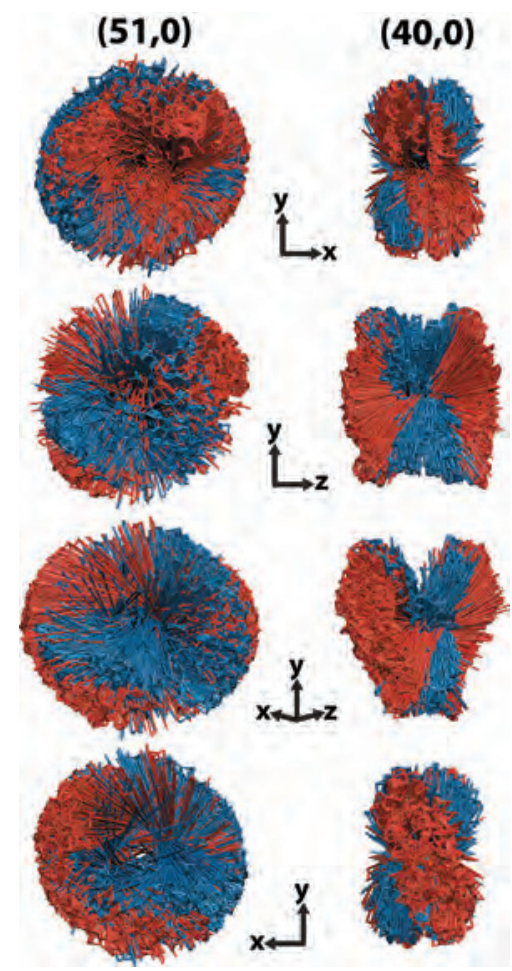

Figura 8 - Ensembles de eixos de cadeia única para o DNA encapsulado ( $q$ $=+0.05 \mathrm{e}^{-} / \mathrm{C}$ ). Cada eixo individual liga dois átomos de fósforo localizados em términos opostos de cada cadeia, resultando assim duas cores para duas cadeias que compõem a dupla hélice. Os nanotubos estão alinhados de forma paralela ao eixo z, com diâmetros $D^{(51,0)}=4 \mathrm{~nm}$ e $D^{(40,0)}=3 \mathrm{~nm}$. rentes perspetivas sobre os sistemas DNA@SWCNT; é de salientar que o nanotubo se encontra orientado ao longo da direção z. Apesar de não representados na Figura 8, resultados idênticos foram obtidos para a topologia hidrofóbica $(51,0)$ [52].

Os ensembles obtidos para as duas topologias são evidentemente distintos. Globalmente, os resultados para o nanotubo $(51,0)$ estão distribuídos de forma quasi-isotrópica, em claro contraste com o ensemble anisotrópico característico do sólido $(40,0)$. Este facto pode ser interpretado em termos de penalizações entrópicas impostas à molécula de DNA quando confinada ao nanoporo mais estreito, penalizações essas que são bastante mitigadas quando o volume-livre aumenta. Neste último caso, os ensembles conformacionais na Figura 8 evidenciam semelhanças com uma forma tipo toroidal no plano $(x, y)$, cujo centro se encontra largamente despopulado. No entanto, mesmo sendo uma entidade flexível, o dodecâmero não pode ser sobre-esticado sem incorrer num aumento do correspondente PMF (Figura 4), e assim a projeção em $(x, y)$ contém regiões opostas simétricas nas fronteiras (domínios próximo das paredes), onde a densidade de eixos de cadeia única é menor.

Os mapas de densidade molecular (Figura 7) revelaram que a molécula de DNA tende a ocupar uma região espacial centralmente localizada em relação ao volume interno do nanoporo $(40,0)$, e, assim, a distribuição dos respetivos ensembles de eixos encontra-se densamente populada naquela região interna. Fisicamente, para se acomodar no plano $(x, y)$ do nanoporo com $D=3 \mathrm{~nm}$, a dupla hélice teria que sofrer uma deformação severa, forçando o esqueleto de fosfatos a dobrar-se em direção ao centro, e assim provocando repulsões eletrostáticas entre eles [60].

\subsection{Cinética}

O estudo das propriedades dinâmicas dos híbridos DNA@SWCNT foi realizado de forma independente e após se terem desligado os potenciais de metadinâmica e de amostragem de chapéu de chuva, $V[\Phi(v), t]$ e $V(\Theta)$, realizando novas simulações de DMC durante $\sim 0,08-0,1 \mu \mathrm{s}$.

A análise temporal das trajetórias moleculares decorre, habitualmente, no âmbito das equações de Stokes-Einstein ou de Green-Kubo [31,61], que se tornaram no método de facto para a obtenção de coeficientes de autodifusão; ambos os formalismos são matematicamente equivalentes [62]. Baidakov e Kozlova determinaram o coeficiente de autodifusão para fluidos de Lennard-Jones monitorizando o deslocamento quadrado médio (equação de Einstein) e as funções de autocorrelação da velocidade (equação de Green-Cubo), concluindo que ambas as metodologias produziam resultados autoconsistentes dentro do erro de cálculo (0,5-1,0\%) [63].

Os dados de transporte obtidos a partir das simulações de CMD são analisados neste trabalho calculando o coeficiente de autodifusão da dupla hélice de DNA, $D_{\text {eff }}$ utilizando a equação de Stokes-Einstein [64] para relacionar $D_{\text {eff }}$ com o deslocamento quadrado médio (MSD) do centro de massa de acordo com a equação 5 , onde $\boldsymbol{r}(t)$ é o vetor posicional no tempo $t$, e os parênteses triangulares representam uma amostragem feita sobre o ensemble de todas as configurações. O cálculo de $D_{\text {eff }}$ a partir da equação 5 
resulta do mapeamento tridimensional do espaço de fases, assim constituindo uma propriedade translacional efetiva.

$$
D_{e f f}=\lim _{t \rightarrow \infty} \frac{1}{6 t}\left\langle[\boldsymbol{r}(t)-\boldsymbol{r}(0)]^{2}\right\rangle
$$

Os resultados para nanotubos hidrofílicos encontram-se registados na Figura 9, juntamente com os componentes individuais de $M S D$ ao longo das direções $x, y$ e $z$; foram já apresentadas as conclusões para um sólido hidrofóbico $(51,0)$ [65]. A título de comparação, apresentam-se também os regimes clássicos de difusão indicados por linhas cinzentas, nomeadamente balístico $\left(M S D \propto t^{2}\right)$, Fick $(M S D \propto t)$ e carreira-única $\left(M S D \propto t^{1 / 2}\right)$. A análise cuidadosa dos dados revela que a translação biomolecular começa no regime de Fick e é de curta duração ( $\leq 2 \mathrm{~ns})$, permitindo nesse regime calcular $D_{\text {eff }}^{(51,0)}=0,954 \times 10^{-9} \mathrm{~m}^{2} / \mathrm{s}$ e $D_{\text {eff }}^{(40,0)}=0,537 \times$ $10^{-9} \mathrm{~m}^{2} / \mathrm{s}$, utilizando a equação de Einstein (equação 5). A magnitude destes valores é metade da propriedade correspondente à topologia hidrofóbica $(51,0), D_{\text {eff }}=1,713 \times 10^{-9}$ $\mathrm{m}^{2} / \mathrm{s}$; a atração eletrostática entre as paredes sólidas e o ácido nucleico induz um abrandamento na difusão molecular em topologias hidrofílicas quando comparada com sólidos puramente hidrofóbicos.

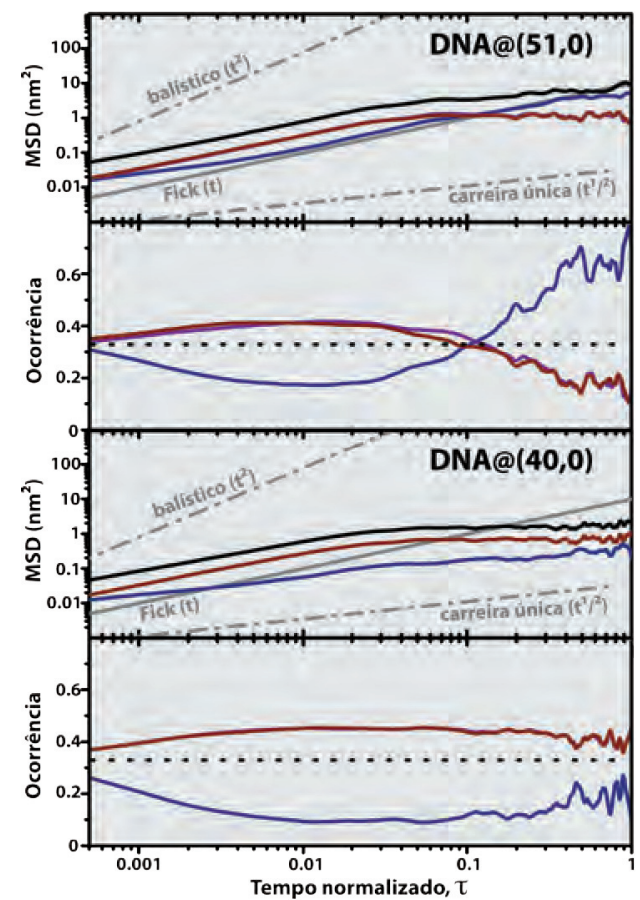

Figura 9 - Representação logarítmica de deslocamento quadrado médio, $M S D=[\boldsymbol{r}(t)-\boldsymbol{r}(0)]^{2}$ e curvas de ocorrência relativa $\left(M S D^{(x),(y),(z)} / M S D^{3 D}\right)$ $\left(q=+0.05 \mathrm{e}^{-/ C}\right)$. As linhas cinzentas correspondem aos regimes clássicos de difusão, balístico $\left(M S D \propto t^{2}\right)$, Fick $(M S D \propto t)$ e carreira única $\left(M S D \propto t^{1 / 2}\right)$, e as linhas tracejadas a preto indicam um patamar de 0,33 nos perfis de ocorrência. O tempo normalizado $(\tau)$ corresponde a $\tau=t / t^{\text {tot }}$, onde $t$ é o tempo medido e $t^{\text {tot }}$ é o tempo total de simulação. Legenda de cores: preto) 3D, púrpura) $x$, encarnado) y e azul) $z$ [59].

Para além do domínio de aplicabilidade da lei de Fick ( $t>2$ ns), ocorre uma transição para o regime de carreira-única e a difusão do DNA segue uma lei $t^{1 / 2}$. A normalização dos perfis de MSD unidirecionais pela correspondente quantidade $3 \mathrm{D}$ de acordo com $M S D^{(x),(y),(z)} / M S D^{3 D}$, revela a existência de um mecanismo nunca antes observado: a difusão é altamente anisotrópica ao longo do nanoporo $(51,0)$, mas não necessariamente no análogo $(40,0)$. Na verdade, a curva de ocorrência de $M S D^{(z)}$ normalizado (Figura 9) contribui com mais de $66 \%$ para o respetivo valor de $M S D^{3 D}$, contribuindo com menos de $33 \%$ no caso do poro $(40,0)$. A existência de um volume de exclusão ao longo de $z$ foi já discutida anteriormente, cuja consequência é o deslocamento dos iões $\mathrm{Cl}^{-}$em direção a términos opostos e tornando o ácido nucleico responsável pela densidade de carga negativa no centro do poro. Esse volume de exclusão é também responsável por dois mecanismos distinctos de translação entre topologias: enquanto que no sólido $(51,0)$ o DNA move-se ao longo do poro favorecendo a direção $z$, quando o diâmetro é reduzido para $3 \mathrm{~nm}$ o modo predileto de translação corresponde a uma rotação ao longo do eixo da dupla hélice [59].

Regra geral, o deslocamento quadrado médio, $\mathrm{MSD}=\left\langle[r(t)-r(0)]^{2}\right\rangle$, pode ser descrito por uma lei do tipo $M S D \propto t^{\kappa}$, onde o expoente é um indicador do modo predominante de translação, nomeadamente $\kappa=2$ (balístico), $k=1$ (Fick) e $\kappa=1 / 2$ (carreira única). Este último caso, onde o MSD aumenta menos do que linearmente com o tempo, cai na categoria geral de sub-difusão, e é trivial demonstrar que, incorporando a lei $t^{\kappa}$ na equação 5 conduz a $D_{\text {eff }} \propto t^{-(1-\kappa)} \propto \operatorname{MSD}^{\frac{-(1-\kappa) !}{\kappa}}$. Torna-se assim evidente que o coeficiente de autodifusão decresce com o aumento do tempo, sendo uma consequência natural à resistência à translação causada pela existência das paredes do sólido; para nanoporos, apenas no limite de tempos muito longos $(\mu s)$ é que este regime sub-difusivo volta ao mecanismo de difusão normal [64]. Assim, os coeficientes de autodifusão obtidos a partir dos dados de MSD registados na Figura 9 devem ser considerados com especial atenção, e utilizados como estimativas da difusão de ácidos nucleicos genomicamente longos em nanotubos carregados.

Para analisar mais detalhadamente este fenómeno determinaram-se curvas de densidade de probabilidade relativas às velocidades instantâneas, como indicado na Figura 10; os resultados são correlacionados utilizando a distribuição de Maxwell-Boltzmann a três dimensões (equação 6) e uma dimensão (equação 7):

$$
\begin{aligned}
& p(v)=\sqrt{\left(\frac{m}{2 \pi k_{B} T}\right)^{3}} 4 \pi v^{2} e^{-\frac{m v^{2}}{2 k_{B} T}} \quad v(x, y, z) \\
& p(v)=\sqrt{\frac{m}{2 \pi k_{B} T}} e^{-\frac{m v^{2}}{2 k_{B} T}} \quad v(x), v(y), v(z)
\end{aligned}
$$

onde $p(v)$ é a probabilidade, $m$ é a massa, $k_{B}$ é a constante de Boltzmann, $T$ é a temperatura absoluta e $v$ a velocidade medida ao longo da direção respetiva.

Torna-se assim evidente que apesar da mobilidade molecular ser anisotrópica, tal facto deve-se essencialmente a razões entrópicas (volume-livre), pois as energias cinéticas $\left(E=\frac{1}{2} m v^{2}\right)$ são muito semelhantes independentemente da direção espacial considerada. Geng e Noy realizaram experiências in vitro com nanotubos incrustados em purinas [28], e demonstraram que os correspondentes híbridos são capazes de transportar cadeias únicas de DNA (ssDNA) 


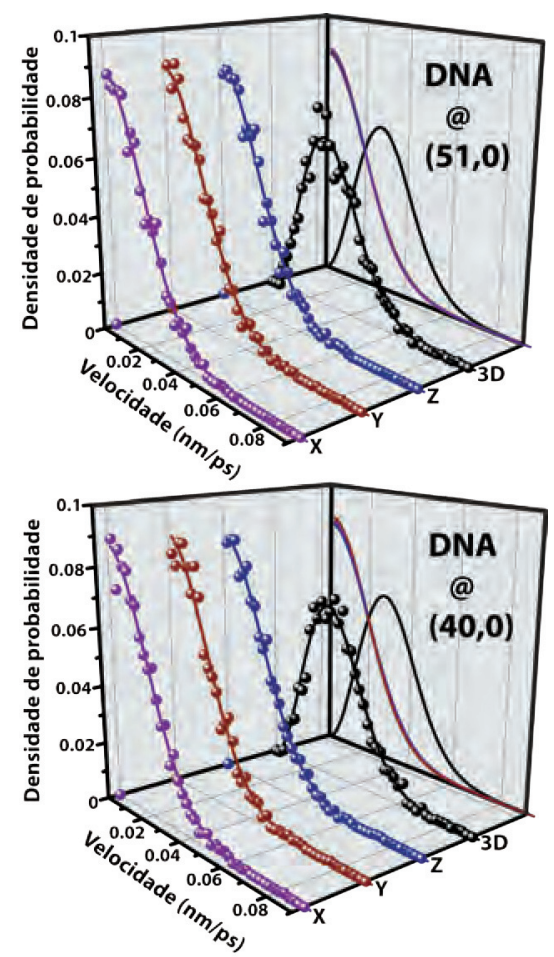

Figura 10 - Perfis de velocidade do centro de massa do DNA@SWCNT $\left(q=+0.05 \mathrm{e}^{-} / \mathrm{C}\right)$. As linhas correspondem a distribuições de Maxwell-Boltzmann (equações 6 e 7), excluindo os primeiros pontos onde a probabilidade $(v=0 \mathrm{~nm} / \mathrm{ps})=0$.

em direção ao interior celular com uma velocidade média de 1,5 nucleótidos/ms. Pei e Gao estudaram a dinâmica de ssDNA's curtos (3 oligonucleótidos) utilizando simulações computacionais [66] enquanto aplicavam um campo gravitacional para induzir difusão; para as suas topologias estreitas, $D=1,36 \mathrm{~nm}$ e $D=1,89 \mathrm{~nm}$, observaram uma velocidade de translação média de $\langle v\rangle \approx 16,67 \mathrm{~m} / \mathrm{s}$. Mais recentemente, Liu et al. construíram transístores elétricos com SWCNTs [67] (comprimentos de $2 \mu \mathrm{m}$ ) e realizaram medidas elétricas para monitorizar a translação de cadeias longas de DNA num padrão de $[\mathrm{KCl}]=1-2 \mathrm{M}$, mas não reportaram os respetivos dados cinéticos.

Tanto quanto é do nosso conhecimento o presente trabalho é o primeiro a estudar a difusão de duplas hélices de DNA através de nanotubos eletricamente carregados, em condições fisiológicas. Considerando que as velocidades instantâneas de translação (3D) são satisfatoriamente descritas por estatísticas de Maxwell-Boltzmann (Figura 10), os respetivos máximos de ocorrência, $\langle v\rangle^{\max }=27,14 \mathrm{~m} / \mathrm{s}$ $(D=4 \mathrm{~nm})$ e $\left\langle v>^{\max }=27,04 \mathrm{~m} / \mathrm{s}(D=3 \mathrm{~nm})\right.$, são aproximadamente o dobro do valor observado por Pei e Gao em nanotubos hidrofóbicos [66] e 3,7-3,8 m/s mais lentos do que a difusão de duplas hélices em topologias $(51,0)$ primitivas $\left(<v>^{\max }=30,8 \mathrm{~m} / \mathrm{s}\right)$ [65].

\section{Conclusão e Perspetivas Futuras}

Quando exposta a sólidos nanoporosos, hidrofóbicos ou hidrofílicos, a dupla hélice de DNA é rapidamente encapsulada de uma forma termodinamicamente espontânea (3,4-15,42 ns), conduzindo a híbridos DNA@SWCNT que exibem um decréscimo significativo da correspondente energia livre de Gibbs ( $\sim 40 \mathrm{~kJ} / \mathrm{mol})$; no entanto, existe um diâmetro crítico de $D=3 \mathrm{~nm}$ em sólidos hidrofóbicos, abaixo do qual o ácido nucleico evita o encapsulamento preferindo permanecer em solução aquosa de $\mathrm{NaCl}$.

O comprimento da biomolécula confinada é semelhante à forma canónica de B-DNA ( $c a .3,8 \mathrm{~nm}$ ), no entanto, as superfícies termodinâmicas exibem mínimos locais de energia-livre consecutivos (separados por $\sim 5 \mathrm{~kJ} / \mathrm{mol}$ ) e correspondentes a uma compressão/expansão da dupla hélice de 0,25-0,5 nm. O ácido nucleico encapsulado mantém mobilidade translacional entre os términos do nanoporo, recorrendo a um mecanismo de difusão anisotrópica e de rotação em torno do eixo da dupla hélice. As imagens nanoscópicas obtidas para os mapas de densidade molecular e de eixos de cadeia única indicam que a molécula favorece o posicionamento em contacto próximo com as paredes internas do nanotubo ou num volume localizado ao longo do eixo principal $z$, onde $(x, y) \approx(0,0)$, dependendo do diâmetro e da densidade de carga elétrica do sólido.

A topologia maior ( $D=4 \mathrm{~nm}$ ) induz sempre uma difusão anisotrópica na molécula de DNA, mecanismo esse que é aniquilado quando o diâmetro decresce para 3 nm e a translação se torna aproximadamente simétrica ao longo de qualquer direção espacial; para além de uma janela inicial de 2-4 ns, onde o DNA se difunde de acordo com a lei de Fick $(\propto t)$, existe uma transição para o regime de carreira única ( $\left.\propto t^{1 / 2}\right)$. Além do mais, a existência de carga elétrica positiva nos sólidos conduz a um abrandamento de $~ 12 \%$ na velocidade instantânea da biomolécula, quando comparada com um sólido $(51,0)$ puramente hidrofóbico.

Para poderem ser utilizados em terapêuticas como agentes de entrega de biomoléculas ao interior da célula viva, os híbridos DNA@SWCNT têm ainda que ser estudados quanto à reversibilidade do mecanismo de encapsulamento. Xue et al. utilizaram agentes de enchimento $\left(\mathrm{C}_{60}\right)$ e atuadores mecânicos (nanofios de Ag) para ejetarem ssDNA de dentro de SWCNTs hidrofóbicos [68], relacionando a possibilidade de ejeção com as interações dispersivas resultantes da externalização da biomolécula. Os agentes $\mathrm{C}_{60}$ utilizados evidenciam interações dispersivas com os nanotubos de $\sim-1800 \mathrm{~kJ} / \mathrm{mol}(\sim-7000 \mathrm{~kJ} / \mathrm{mol}$ para os nanofios de Ag), uma ordem de magnitude acima dos valores observados para encapsulamento em sólidos $(51,0)$ [52], e assim validando a hipótese daqueles mecanismos serem empregues na externalização de dsDNA.

\section{Agradecimentos}

O trabalho foi desenvolvido no Laboratório Associado para a Química Verde LAQV que é financiado por fundos nacionais da FCT/MEC (UID/QUI/50006/2013) e cofinanciado pelo FEDER ao abrigo do Acordo de Parceria PT2020 (POCI-01-0145-FEDER - 007265); alguns dos resultados foram obtidos com o apoio da Iniciativa de Rede Nacional Portuguesa (https://wiki.ncg.ingrid.pt). e/ou no Departamento de Engenharia Química da Univ. Wisconsin-Madison. F.J.A.L. Cruz agradece o apoio financeiro da FCT/MCTES (Portugal) através dos projetos e bolsas SFRH/BPD/45064/2008, EXCL/QEQ-PRS/0308/2012 e REQUIMTE/BPD/004/2016.

\section{Dedicatória}

Para Fernando Lino da Cruz, por ocasião do seu $78 .^{\circ}$ aniversário, em reconhecimento da sua força de viver e incessante apoio. Bem hajas... 


\section{Bibliografia}

[1] S. Iijima, Nature 354 (1991) 56-58.

[2] S. Iijima, T. Ichihashi, Nature 363 (1993) 603-605.

[3] D.S. Bethune, C.H. Kiang, M.S.d. Vries, G. Gorman, R. Savoy, J. Vasquez, R. Beyers, Nature 363 (1993) 605-607.

[4] R. Saito, G. Dresselhaus, M.S. Dresselhaus, Physical Properties of Carbon Nanotubes, Imperial College Press, London, 1998.

[5] R.H. Baughman, A.A. Zakhidov, W.A. de Heer, Science 297 (2002) 787-792.

[6] S.B. Sinnott, R. Andrews, Crit. Rev. Sol. State Mat. Sci. 26 (2001) 145-249.

[7] S.Y. Hong, G. Tobias, B. Ballesteros, F.E. Oualid, J.C. Errey, K. Doores, A.I. Kirkland, P.D. Nellist, M.L.H. Green, B.G. Davis, J. Am. Chem. Soc. 129 (2007) 10966-10967.

[8] Z. Mao, S.B. Sinnott, J. Phys. Chem. B, 105 (2001) 6916-6924.

[9] D. Cao, X. Zhang, J. Chen, W. Wang, J. Yun, J. Phys. Chem. B107 (2003) 13286-13292.

[10] P. Kowalczyk, L. Solarz, D.D. Do, A. Samborski, J.M.D. MacElroy, Langmuir 22 (2006) 9035-9040.

[11] M.R. LaBrosse, W. Shi, J.K. Johnson, Langmuir 24 (2008) 9430-9439.

[12] T. Shiraki, A. Tsuzuki, F. Toshimitsu, N. Nakashima, Chem. Eur. J. 22 (2016) 4774-4779.

[13] W. Lv, Chem. Phys. Lett. 514 (2011) 311-316.

[14] X. Zhao, J.K. Johnson, J. Am. Chem. Soc. 129 (2007) 10438-10445.

[15] P. Liu, Ind. Eng. Chem. Res. 52 (2013) 13517-13527.

[16] F.J.A.L. Cruz, I.A.A.C. Esteves, S. Agnihotri, J.P.B. Mota, J. Phys. Chem. C 115 (2011) 2622-2629.

[17] F.J.A.L. Cruz, E.A. Müller, J.P.B. Mota, RSC Advances 1 (2011) 270-281.

[18] F.J.A.L. Cruz, J.P.B. Mota, Phys. Rev. B 79 (2009) 165426.

[19] F.J.A.L. Cruz, E.A. Müller, Adsorption 15 (2009) 1-12.

[20] D.S. Rawat, M.M. Calbi, A.D. Migone, J. Phys. Chem. C 111 (2007) 12980-12986.

[21] G. Stan, M.J. Bojan, S. Curtarolo, S.M. Gatica, M.W. Cole, Phys. Rev. B 62 (2000) 2173-2180.

[22] U. Zimmerli, P. Koumoutsakos, Biophys. J. 94 (2008) 2546-2557.

[23] M. Wiggin, C. Tropini, V. Tabard-Cossa, N.N. Jetha, A. Marzialiy, Biophys. J. 95 (2008) 5317-5323.

[24] J.D. Watson, F.H.C. Crick, Nature 171 (1953) 737-738.

[25] H.R. Drew, R.M. Wing, T. Takano, C. Broka, S. Tanaka, K. Itakura, R.E. Dickerson, Proc. Nat. Acad. Sci. 78 (1981) 2179-2183.

[26] S. Kumar, R. Rani, N. Dilbaghi, K. Tankeshwara, K.-H. Kim, Chem. Soc. Rev. 46 (2017) 158-196.

[27] S.K. Vashist, D. Zheng, G. Pastorin, K. Al-Rubeaan, J.H.T. Luong, F.-S. Sheu, Carbon 49 (2011) 4077- 4097.

[28] J. Geng, K. Kim, J. Zhang, A. Escalada, R. Tunuguntla, L.R. Comolli, F.I. Allen, A.V. Shnyrova, K.R. Cho, D. Munoz, Y.M. Wang, C.P. Grigoropoulos, C.M. Ajo-Franklin, V.A. Frolov, A. Noy, Nature 514 (2014) 612-615.

[29] K. Kim, J. Geng, R. Tunuguntla, L.R. Comolli, C.P. Grigoropoulos, C.M. Ajo-Franklin, A. Noy, Nano Lett. 14 (2014) 7051-7056.

[30] H. Kumar, Y. Lansac, M.A. Glaser, P.K. Maiti, Soft Matter 7 (2011) 5898-5907.

[31] M.P. Allen, D.J. Tildesley, Computer Simulation of Liquids, Clarendon Press, Oxford, 1990.

[32] J.S. Rowlinson, F.L. Swinton, Liquids and Liquid Mixtures, Butterworths, London, 1982.
[33] J. Wang, P. Cieplak, P.A. Kollman, J. Comput. Chem. 21 (2000) 1049-1074.

[34] K. Lindorff-Larsen, S. Piana, K. Palmo, P. Maragakis, J.L. Klepeis, R.O. Dror, D.E. Shaw, Proteins 78 (2010) 1950-1958.

[35] A. Noy, I. Soteras, F.J. Luque, M. Orozco, Phys. Chem. Chem. Phys. 11 (2009) 10596-10607.

[36] W.L. Jorgensen, J. Chandrasekhar, J.D. Madura, R.W. Impey, M.L. Klein, J. Chem. Phys. 79 (1983) 926-935.

[37] Y. Wang, D.R. Tree, K.D. Dorfman, Macromolecules 44 (2011) 6594-6604.

[38] James A. Elliott, J.K.W. Sandler, A.H. Windle, R.J. Young, M.S.P. Shaffer, Phys. Rev. Lett. 92 (2004) 095501.

[39] K. Kobayashi, R. Kitaura, F. Nishimura, H. Yoshikawa, K. Awaga, H. Shinohara, Carbon 49 (2011) 5173-5179.

[40] F.J.A.L. Cruz, J.J.de Pablo, J.P.B. Mota, RSC Adv. 4 (2014) 1310-1321.

[41] F.J.A.L. Cruz, J.P.B. Mota, J. Phys. Chem. C 120 (2016) 20357-20367.

[42] B. Hess, C. Kutzner, D.v.d. Spoel, E. Lindahl, J. Chem. Theory Comp. 4 (2008) 435-447.

[43] W. Humphrey, A. Dalke, K. Schulten, J. Molec. Graphics 14 (1996) 33-38.

[44] S. Nosé, J. Chem. Phys. 81 (1984) 511-519.

[45] W.G. Hoover, Phys. Rev. A 31 (1985) 1695-1697.

[46] M. Parrinello, A. Rahman, J. Appl. Phys. 52 (1981) 7182-7190.

[47] T. Darden, D. York, L. Pedersen, J. Chem. Phys. 98 (1993) 10089-10092.

[48] U. Essmann, L. Perera, M.L. Berkowitz, T. Darden, H. Lee, L.G. Pedersen, J. Chem. Phys. 103 (1995) 8577-8592.

[49] A. Barducci, G. Bussi, M. Parrinello, Phys. Rev. Lett. 100 (2008) 020603.

[50] O. Valsson, P. Tiwary, M. Parrinello, Ann. Rev. Phys. Chem. 67 (2016) 159-184

[51] A. Laio, F.L. Gervasio, Rep. Prog. Phys. 71 (2008) 126601.

[52] F.J.A.L. Cruz, J.J.de Pablo, J.P.B. Mota, J. Chem. Phys. 140 (2014) 225103.

[53] G.M. Torrie, J.P. Valleau, J. Comput. Phys. 23 (1977) 187-199.

[54] J. Kastner, WIREs Comput. Mol. Sci. 1 (2011) 932- 942.

[55] B. Roux, Comp. Phys. Comm. 91 (1995) 275-282.

[56] S. Kumar, D. Bouzida, R.H. Swendsen, P.A. Kollman, J.M. Rosenberg, J. Comp. Chem. 13 (1992) 1011-1021.

[57] A. Grossfield, WHAM: the weighted histogram analysis method 2011.

[58] M. Bonomi, D. Branduardi, G. Bussi, C. Camilloni, D. Provasi, P. Raiteri, D. Donadio, F. Marinelli, F. Pietrucci, R.A. Broglia, M. Parrinello, Comp. Phys. Comm. 180 (2009) 1961-1972.

[59] F.J.A.L. Cruz, J.P.B. Mota, J. Phys. Chem. C (submetido), (2017).

[60] X. Qiu, D.C. Rau, V.A. Parsegian, L.T. Fang, C.M. Knobler, W.M. Gelbart, Phys. Rev. Lett. 106 (2011) 028102.

[61] J.M. Haile, Molecular Dynamics Simulation: Elementary Methods, Wiley, New York, 1992.

[62] R. Zwanzig, Annu. Rev. Phys. Chem. 16 (1965) 67-102.

[63] V.G. Baidakov, Z.R. Kozlova, Chem. Phys. Lett. 500 (2010) 23-27.

[64] J. Karger, ChemPhysChem 16 (2015) 24-51.

[65] F.J.A.L. Cruz, J.J.de Pablo, J.P.B. Mota, Biochem. Eng. J. 104 (2015) 41-47.

[66] Q.X. Pei, C.G. Lim, Y. Cheng, H. Gao, J. Chem. Phys. 129 (2008) 125101.

[67] H. Liu, J. He, J. Tang, H. Liu, P. Pang, D. Cao, P. Krstic, S. Joseph, S. Lindsay, C. Nuckolls, Science 327 (2010) 64-67.

[68] Q. Xue, N. Jing, L. Chu, C. Ling, H. Zhang, RSC Adv. 2 (2012) 6913-6920. 